\title{
eJRIEPS
}

Ejournal de la recherche sur l'intervention en éducation physique et sport

15 | 2008

Varia

\section{Message de Frédéric Aubert}

Frédéric Aubert

\section{OpenEdition}

Journals

Édition électronique

URL : https://journals.openedition.org/ejrieps/5808

DOI : 10.4000/ejrieps.5808

ISSN : 2105-0821

Éditeur

ELLIADD

\section{Référence électronique}

Frédéric Aubert, « Message de Frédéric Aubert », eJRIEPS [En ligne], 15| 2008, mis en ligne le 01 juillet 2008, consulté le 03 mai 2021. URL : http://journals.openedition.org/ejrieps/5808 ; DOI : https:// doi.org/10.4000/ejrieps.5808

\section{(c) (1)}

La revue eJRIEPS est mise à disposition selon les termes de la Creative Commons Attribution 4.0 International License. 
Message de Frédéric Aubert

Frédéric Aubert

Professeur à I'INSEP, préparateur physique à la DTN de Basket-ball

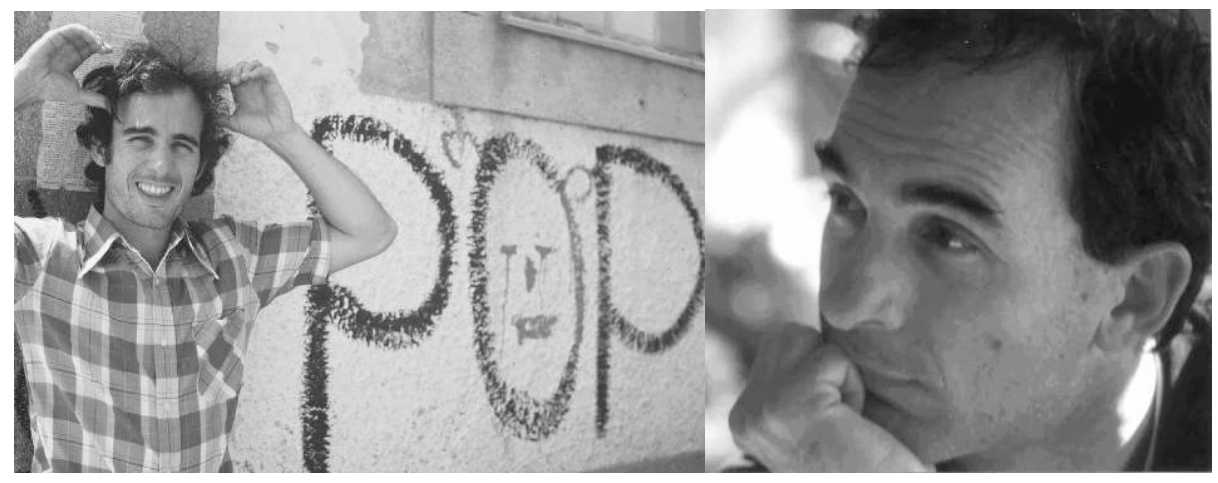

Les mots clé de ce message sont:

Didactique- Technologie - Entraîneurs - et bien sur Alain DUREY

Bonjour Alain, bonjour à tous,

Oui Alain, tu es toujours présent tel un maître JEDI dont l'influence n'a plus besoin du corps, et dont l'esprit perpétue la démarche didactique.

Avec toi, avec Jacqueline et Daniel aussi, j'ai appris à soigner le Syndrome Institutionnel de Didactique Aigu, vous savez, le SIDA de l'E.P.S. Comment? Grâce à vos IMPULSIONS technologiques bien sûr! Pour les enseignants et entraîneurs, désormais, la technologie des A.P.S. est l'équivalent du nord magnétique des marins, afin qu'au-delà des courants et des modes jamais ne soit perdue la boussole didactique.

«Questionner les évidences et refuser la simplicité ». Tu as souvent agité ce slogan cher à Jean-Louis pour bouger nos neurones d'homme de terrain, pousser notre réflexion didactique plus avant. Ceci m‘a permis de faire tout le contraire au cœur même de l'intervention : « traiter les évidences et mettre en œuvre dans la simplicité ».

Cher Alain, à défaut de m'avoir transformé en enseignant-chercheur, tu m'as confirmé comme "entraîneur-trouveur ", car éclairé des connaissances scientifiques. Que tu sois en hologramme, lorsque je veux revoir tes traits, ou bien en esprit lorsque j'élabore des modèles d'entraînement, tu es le scientifique ouvert et à la rigueur congruente que les entraîneurs ont longtemps attendu. Cher Alain, tu es, demeure et nous accompagne dans ce troisième millénaire.

A tous, je vous souhaite d'excellentes J.A.D. 